\title{
Éric Vallet, Sandra Aube, Thierry Kouamé (dirs.). Lumières de la sagesse. Écoles médiévales d'Orient et d'Occident.
}

Paris, Publications de la Sorbonne/Institut du Monde Arabe, 2013, 424 p.

\section{Camille Rhoné}

\section{OpenEdition \\ Journals}

\section{Édition électronique}

URL : http://journals.openedition.org/abstractairanica/41231

DOI : 10.4000/abstractairanica.41231

ISSN : 1961-960X

Éditeur :

CNRS (UMR 7528 Mondes iraniens et indiens), Éditions de l'IFRI

\section{Référence électronique}

Camille Rhoné, «Éric Vallet, Sandra Aube, Thierry Kouamé (dirs.). Lumières de la sagesse. Écoles médiévales d'Orient et d'Occident. », Abstracta Iranica [En ligne], Volume 34-35-36 | 2017, document 1, mis en ligne le 15 juillet 2016, consulté le 28 septembre 2020. URL : http://journals.openedition.org/ abstractairanica/41231; DOI : https://doi.org/10.4000/abstractairanica.41231

Ce document a été généré automatiquement le 28 septembre 2020.

Tous droits réservés 


\section{Éric Vallet, Sandra Aube, Thierry Kouamé (dirs.). Lumières de la sagesse. Écoles médiévales d'Orient et d'Occident.}

Paris, Publications de la Sorbonne/Institut du Monde Arabe, 2013, 424 p.

\section{Camille Rhoné}

\section{RÉFÉRENCE}

Éric Vallet, Sandra Aube, Thierry Kouamé (dirs.). Lumières de la sagesse. Écoles médiévales d'Orient et d'Occident. Paris, Publications de la Sorbonne/Institut du Monde Arabe, 2013, $424 \mathrm{p}$.

1 Cet ouvrage a été publié à l'occasion de l'exposition Lumières de sagesse qui s'est tenue à l'Institut du Monde Arabe de septembre 2013 à janvier 2014 grâce aux activités de la Chaire de dialogue des cultures établie à l'Université Paris I, en partenariat avec l'Université al-Imam Ibn Sa'ūd de Riyad (Arabie Saoudite). Le sujet très vaste - les « institutions scolaires médiévales [...] de l'Écosse à l'Ethiopie, de l'Andalousie à l'Inde » (p. xv) - est abordé en dépit des cloisonnements historiographiques entre Orient et Occident, cloisonnements que les directeurs du projet et les nombreux contributeurs entendent ici dépasser.

2 L'ouvrage, très richement illustré, inclut des articles de synthèse, des encarts sur des recherches récentes et des notices sur les objets exposés (nombreux manuscrits, mais aussi étui à calame (p.97), stylet (p. 286), «lampe de mosquée» (p. 197), figure de tombeau de maître bolonais (p. 275), etc.). L'ensemble est réparti en quatre parties : la première est consacrée à la diversité des écoles d'un vaste pourtour méditerranéen médiéval ( $\mathrm{V}^{\mathrm{e}-\mathrm{XII}}{ }^{\mathrm{e}} \mathrm{s}$.) et à leurs liens avec le milieu urbain. Les deuxième et troisième parties mettent en regard respectivement madrasas et universités : la période du $\mathrm{XI}^{\mathrm{e}}$ au 
$\mathrm{XVI}^{\mathrm{e}}$ s. est marquée par «un souci de diffusion plus large des savoirs et [...] le poids accru des maitres au sein de la société » (p.xviii). C'est précisément la question de l'autorité du maître qui est au cœur de la dernière partie. Parallèlement à la place de cette figure et à la formation progressive de lieux pérennes de transmission du savoir, l'ouvrage interroge aussi le rôle du livre dans cette transmission. De fait, de nombreux textes du Moyen Âge, religieux et profanes, sont ici abordés : recueils de hadịtss, traités médicaux, écrits philosophiques grecs, manuel latin de magie universitaire pour parvenir à la science infuse (p. 301), etc.

3 Les articles de synthèse, de longueur forte inégale, incluent quelques textes inédits, mais aussi la traduction d'extraits de textes de chercheurs arabophones ou anglophones. En fin d'ouvrage, une chronologie succincte porte sur le cadre politique et l'histoire de l'enseignement de Byzance, du «Proche-Orient et l'Islam» et de l'Occident latin. À cela s'ajoutent un glossaire, une bibliographie suivant l'ordre des quatre parties de l'ouvrage, un index des lieux et des noms. On peut regretter l'absence d'un index des sujets et objets qui auraient permis de mieux exploiter cette publication très riche.

\section{AUTEURS}

\section{CAMILLE RHONÉ}

Université Aix-Marseille 